\title{
Classificação e diagnóstico do estado de conservação de uma via em pavimentação asfáltica do município de Caruaru, Pernambuco, Brasil
}

Classification and conservation diagnosis of an asphalt paving road in the city of Caruaru, Pernambuco, Brazil

Clasificación y diagnóstico del estado de conservación de una carretera asfaltada en el municipio de Caruaru, Estado de Pernambuco, Brasil

Yago Ryan Pinheiro dos Santos ORCID: https://orcid.org/0000-0002-4280-4336 Universidade Federal de Pernambuco, Brasil E-mail: yago_ryan@hotmail.com

Carlos Eduardo Braga Barbosa ORCID: https://orcid.org/0000-0002-8825-3816 Centro Universitário Maurício de Nassau, Brasil E-mail: carloseduardobb@outlook.com Jair José de Lima ORCID: https://orcid.org/0000-0002-8570-5485 Centro Universitário Maurício de Nassau, Brasil E-mail: jairlimaeng@gmail.com

Mirelly Maria Monteiro Meneses ORCID: https://orcid.org/0000-0003-1755-6120 Centro Universitário Maurício de Nassau, Brasil E-mail: mmeneses.engcivil@gmail.com

Paula Dayanne Lima Nascimento ORCID: https://orcid.org/0000-0001-8669-1604 Centro Universitário Maurício de Nassau, Brasil

E-mail: pauladayannenascimento@gmail.com

\begin{abstract}
Resumo
A presença de patologias nas vias asfálticas gera desconforto e insegurança para os seus usuários, sendo assim, necessária a identificação dessas patologias e sua devida correção. O objetivo desse estudo é identificar e analisar as principais patologias existentes na Avenida Maria Merandoilina, e os impactos causados nessa via que liga os bairros Nossa Senhora das Dores e Rendeiras. Utilizou-se o método de levantamento visual contínuo, do DNIT, para avaliar a qualidade física da avenida, visando mostrar sua classificação de qualidade e quais os reparos necessários para restaurar a qualidade da avenida. A via apresenta 118 pontos de danos e defeitos de diversas patologias ao longo do 1 $\mathrm{Km}$ analisado, o que classifica a avenida como ruim em seu estado geral. As patologias que se destacaram no trecho analisado foram os desgastes, remendos e trincas couro de jacaré, de modo que a via necessita de recapeamento com correções prévias, afim de sanar ou mitigar as patologias encontradas e proporcionar um tráfego de qualidade e com segurança. De acordo com os parâmetros normativos, a via de estudo demanda reparos e cuidados, devido ao seu elevado grau patológico que compromete sua utilização de forma eficiente, afim de proporcionar de forma segura o tráfego de automóveis e pedestres que utilizam a via.
\end{abstract}

Palavras-chave: Levantamento visual; Manifestações patológicas; Buracos; Pavimento flexível.

\begin{abstract}
The presence of pathologies in the asphalt pathways generates discomfort and insecurity for its users, making it necessary to identify these pathologies and correct them. The objective of this study is to identify and analyze the main pathologies existing on Avenida Maria Merandoilina, and the impacts caused on this road that connects the Nossa Senhora das Dores and Rendeiras neighborhoods. DNIT's continuous visual survey method was used to assess the physical quality of the avenue, in order to show its quality classification and which repairs were necessary to restore the quality of the avenue. The road has 118 points of damage and defects of various pathologies along the 1 $\mathrm{km}$ analyzed, which classifies the avenue as bad in general. The pathologies that stood out in the analyzed stretch were wear, patches and cracks alligator leather, so that the road needs to be resurfaced with prior corrections, in order to remedy or mitigate the pathologies found and provide quality and safe traffic. According to the normative
\end{abstract}


parameters, the study road requires repairs and care, due to its high pathological degree that compromises its efficient use, in order to safely provide the traffic of cars and pedestrians using the road.

Keywords: Visual survey; Pathologies; Holes; Flexible paving.

\begin{abstract}
Resumen
La presencia de patologías en las carreteras asfaltadas genera incomodidad e inseguridad para sus usuarios, por lo que es necesario identificar estas patologías y su corrección. El objetivo de este estudio es identificar y analizar las principales patologías en la Avenida Maria Merandoilina, y los impactos causados en esta vía que conecta los barrios Nossa Senhora das Dores y Rendeiras. Para evaluar la calidad física de la avenida se utilizó el método de encuesta visual continua, del DNIT, con el objetivo de mostrar su clasificación de calidad y qué reparaciones son necesarias para restaurar la calidad de la avenida. La carretera presenta 118 puntos de daños y defectos de diversas patologías a lo largo del $1 \mathrm{~km}$ analizado, lo que clasifica la avenida como mala en su estado general. Las patologías que destacaron en el tramo analizado fueron el desgaste, los parches y las grietas de piel de cocodrilo, por lo que la carretera necesita una repavimentación con correcciones previas para remediar o mitigar las patologías encontradas y proporcionar un tráfico de calidad y seguridad. De acuerdo con los parámetros normativos, la vía de circulación requiere de reparaciones y cuidados, debido a su elevada gravedad patológica que compromete su uso de forma eficiente, además de proporcionar de forma segura el tránsito de automóviles y peatones que utilizan la vía.
\end{abstract}

Palabras clave: Levantamiento visual; Manifestaciones patológicas; Buracos; Pavimento flexible.

\title{
1. Introdução
}

A infraestrutura trata-se de um conjunto de elementos estruturais que auxiliam no desenvolvimento socioeconômico de uma região. Com o desenvolvimento constante, surge a necessidade de recursos e meios que facilitem a locomoção e o transporte de cargas, além disso, o aumento do consumismo tem exigido cada vez mais por pistas e rodovias pavimentas de qualidade e, devido a isso, é indispensável o uso e a conservação e manutenção das pistas de rolamento afim de proporcionar um tráfego de qualidade com segurança.

Apesar de ser um país com dimensões continentais, o Brasil, como citado por Silva (2020), possui grande dependência do transporte rodoviário, uma vez que este é o principal modal de transporte utilizado no país para transporte de cargas, e é também, o responsável pela locomoção de cerca de $96 \%$ dos passageiros.

Pavimento é uma estrutura de múltiplas camadas de espessuras finitas, construída sobre a superfície final de terraplenagem, destinada técnica e economicamente a resistir aos esforços oriundos do tráfego de veículos e do clima, e a propiciar aos usuários melhoria nas condições de rolamento, com conforto, economia e segurança (Bernucci et al., 2006). Segundo o DNIT (2006), de uma forma geral, os pavimentos são classificados em 3 tipos distintos, flexíveis, semirrígidos e rígidos.

A pavimentação flexível, também conhecida por pavimentação asfáltica, conforme a Votorantim (2016), demanda investimentos menores para sua execução, o que a torna a melhor opção na maioria das situações, devido sua abundância em mão de obra, sua rapidez e facilidade de execução e manutenção, além de ser mais sustentável, pois o revestimento asfáltico pode ser reciclado de forma parcial ou inteiramente. O pavimento flexível possui a vantagem de existir um maior número de empresas que possuem mão de obra especializada, além do maquinário e equipamentos necessários para sua execução. (Ribas, 2017).

Devido ao baixo índice de investimento em manutenção e restauração de pavimentos, ocasionado pela má administração pública, o que gera um crescimento desordenado do índice patológico das vias, danificando as estruturas existentes causando desconforto e uma queda na segurança dos usuários dessas rodovias. (Rocha, Ferreira \& Borba, 2019) Ainda devido à falhas administrativas, onde o retorno das necessidades de restauração e manutenção das vias não são revertidas como deveriam, ocorre um acumulo de falhas, ocasionando falta de sinalização adequada, patologias e trechos em estado crítico, como aponta a pesquisa da Confederação Nacional de Transportes (CNT, 2016), fornecendo aos usuários, motoristas e pedestres, um serviço de baixa qualidade e em casos mais críticos, perigoso. 
As causas para o surgimento das patologias em pavimentos asfálticos podem ser a má execução do projeto, problemas construtivos, falha na seleção dos materiais, inadequações nas alternativas de conservação e manutenção, assim como as solicitações do tráfego e ações climáticas, também influenciam na deterioração do pavimento (Pereira, 2018).

De acordo com dados da CNT (2016), referente às rodovias sob gestão pública, resultou-se que $67,1 \%$ das rodovias do país apresentam patologias de modo que conforme o grau de deficiência apresentada nas vias elas possam ser classificadas como regular, ruim ou péssima. Os agentes patológicos mais comuns são as chuvas torrenciais, as sobrecargas dos veículos além de má execução das pistas de rolamento, seja por materiais de baixa qualidade ou espessuras inadequadas ou insuficientes. Uma rodovia em condições ruins de uso, além de causar prejuízos ambientais, redução no conforto e segurança de cargas e passageiros, acarreta também no aumento do custo operacional do transporte, uma vez que a qualidade da pavimentação possui impacto direto no desempenho do transporte rodoviário e na economia do país. (CNT, 2017)

Esse trabalho tem por objetivo a identificação das patologias presentes na Avenida Maria Merandoilina, via que liga os bairros de Nossa Senhora das Dores e Rendeiras da cidade de Caruaru-PE, e sua classificação em decorrência dessas manifestações patológicas, afim de diagnosticar suas causas, proporcionando identificação dos danos e defeitos presentes na avenida, além de averiguar o impacto à segurança que essas manifestações patológicas causam aos usuários da mesma.

\section{Metodologia}

A presente seção trata-se da caracterização do local de estudo e sua importância para a sociedade local de Caruaru, apresentando os equipamentos e materiais utilizados para a obtenção dos dados levantados, além de retratar as maneiras e os métodos empregados para qualificar a avenida estudada.

\subsection{Apresentação da Área de Estudo}

O trabalho foi desenvolvido na Avenida Maria Merandoilina, nas dependências da cidade de Caruaru-PE, cujas coordenadas geográficas são $08^{\circ} 17^{\prime} 00^{\prime \prime}$ de latitude Sul, 3558'34" de longitude Oeste e altitude de $545 \mathrm{~m}$. A presente via é disposta de uma faixa de rolamento de $8,10 \mathrm{~m}$ de largura, sem acostamento ao longo do seu perímetro, com um comprimento efetivo de 1,00 km, localizada próxima ao centro urbano, com acessos a bairros residenciais, por intermédio de vias locais e coletoras, fazendo uma conexão direta do centro para zonas locais. Devido ao intenso tráfego e fluxo de 28 automóveis, a via possui patologias e deficiências ao longo do trecho, o que acarreta em ineficiência, perigos e transtornos no trânsito.

\subsection{Levantamento de dados}

O registro e a condução do projeto se deram a partir da identificação quantitativa dos erros e defeitos da via Avenida Maria Merandoilina, por meio de registro fotográfico, aliado de trena de bolso Starret de 5 metros, além de régua de alumínio. As avaliações patológicas ocorreram através da identificação e qualificação dos erros do trecho, além de registro e medição dos mesmos, discutindo-se suas possíveis causas, montando-se uma estatística da qualidade da avenida, além da identificação dos trechos irregulares, assim, agindo para um aprimoramento da via, promovendo uma locomoção rápida e segura.

O levantamento do material de estudo do trabalho se deu durante o dia 23 de setembro de 2020, onde foi coletado em todo o trecho da avenida os pontos patológicos que se faziam presentes em seu contorno, com o registro fotográfico e classificação das patologias houve um preenchimento de tabelas para serem obtidos índices que darão subsídio para classificar de modo geral a qualidade da avenida. 


\subsection{Procedimentos para diagnóstico}

Por meio da normativa de Levantamento Visual Contínuo para avaliação da superfície de pavimentos flexíveis e semirrígidos 008/2003 do DNIT (2003) colheram-se os dados, procedimentos e métodos que devem ser aplicados no trecho estudado, para obtenção de seus resultados e classificação quanto a sua condição física, gerando assim uma categorização direta das condições da via, relacionado-se com os impactos decorrentes a frequência patológica na avenida. No Anexo A pode-se observar a codificação e a descrição de cada variável patológica, que contém nos anexos seguintes da norma.

Os cálculos se iniciam com preenchimento de uma tabela, ver Anexo B, onde nela é feito uma listagem com todas as patologias encontradas no trecho estudado, já classificando-as de acordo com sua tipologia, que varia entre os vários tipos patológicos apresentados aqui neste trabalho, no referencial teórico e com o fim deste preenchimento, de forma visual é encontrado o valor do ICPF. Por meio dos valores do ICPF, já temos uma descrição prévia quanto a agressão e correções necessárias para a avenida, ver na Tabela 1.

Tabela 1. Conceitos do ICPF.

\begin{tabular}{c|l|c}
\hline CONCEITO & \multicolumn{1}{|c|}{ DESCRIÇÃO } & ICPF \\
\hline Ótimo & NECESSITA APENAS DE CONSERVAÇÃO ROTINEIRA & $5-4$ \\
\hline Bom & $\begin{array}{l}\text { APLICAÇÃO DE LAMA ASFÁLTICA - Desgaste superficial, trincas não muito } \\
\text { severas em áreas não muito extensas }\end{array}$ & $4-3$ \\
\hline Regular & $\begin{array}{l}\text { CORREÇÃO DE PONTOS LOCALIZADOS OU RECAPEAMENTO - } \\
\text { pavimento trincado, com "panelas" e remendos pouco frequentes e com } \\
\text { irregularidade longitudinal ou transversal. }\end{array}$ & $3-2$ \\
\hline Ruim & $\begin{array}{l}\text { RECAPEAMENTO COM CORREÇÕES PRÉVIAS - defeitos generalizados com } \\
\text { correções prévias em áreas localizadas - remendos superficiais ou profundos. }\end{array}$ & $2-1$ \\
\hline & $\begin{array}{l}\text { RECONSTRUÇÃO - defeitos generalizados com correções prévias em toda a } \\
\text { extensão. Degradação do revestimento e das demais camadas - infiltração de água } \\
\text { e descompactação da base }\end{array}$ & $1-0$ \\
\hline
\end{tabular}

Fonte: DNIT (2003).

Sabendo do índice de gravidade, obtido através da Tabela 2, é possível identificar os valores correspondentes aos pesos, na Tabela 3, para o cálculo do IGGE.

Tabela 2. Pesos para cálculo.

\begin{tabular}{c|c|c|c}
\hline GRAVIDADE & Pt & Poap & Ppr \\
\hline 3 & 0,65 & 1,00 & 1,00 \\
\hline 2 & 0,45 & 0,70 & 0,80 \\
\hline 1 & 0,30 & 0,60 & 0,70 \\
\hline
\end{tabular}

Fonte: DNIT (2003).

Por fim, com os valores de ICPF e IGGE obtemos o IES, como mostra Tabela 3, que dará o estado da superfície do pavimento, valor esse que pode ser compreendido de 0 a 10, juntamente com seu código e conceito. 
Tabela 3. Índice do estado da superfície do pavimento

\begin{tabular}{c|c|c|c}
\hline DESCRIÇÃO & IES & CÓDIGO & CONCEITO \\
\hline IGGE $\leq 20$ e ICPF $>3,5$ & 0 & A & ÓTIMO \\
\hline IGGE $\leq 20$ e ICPF $\leq 3,5$ & 1 & B & BOM \\
\hline $20 \leq$ IGGE $\leq 40$ e ICPF $>3,5$ & 2 & & REGULAR \\
\hline $20 \leq$ IGGE $\leq 40$ e ICPF $\leq 3,5$ & 3 & C & RUIM \\
\hline $40 \leq$ IGGE $\leq 60$ e ICPF $>2,5$ & 4 & & PÉSSIMO \\
\hline $40 \leq$ IGGE $\leq 60$ e ICPF $\leq 2,5$ & 5 & D & \\
\hline $60 \leq$ IGGE $\leq 90$ e ICPF $>2,5$ & 7 & & E \\
\hline $60 \leq$ IGGE $\leq 90$ e ICPF $\leq 2,5$ & 8 & &
\end{tabular}

Fonte: DNIT (2003).

Conclui-se então que o cálculo será mediante o levantamento do comprimento da via, que possui $1 \mathrm{~km}$ de extensão, assim, obtendo-se cada um desses itens, temos a classificação quanto a condição da avenida.

\section{Resultados e Discussão}

Esta seção apresenta os resultados obtidos através da metodologia citada anteriormente, bem como o registro das patologias identificadas ao longo do $1 \mathrm{Km}$ analisado da avenida em estudo, juntamente à sua nomenclatura, de modo que também apresenta uma amostragem numérica das anomalias presentes na via, evidenciando a classificação da pista, que pode variar conforme a frequência e o peso patológico, ocasionando, com base normativa, sua classificação diante das condições de uso da via analisada.

\subsection{Resultados do levantamento patológico}

Ao realizar o levantamento do índice e frequência patológica no trecho de $1 \mathrm{Km}$ da avenida de estudo, expõe-se os defeitos, danos e dados coletados, destacando as condições em que a via se encontra, com as dimensões e os tipos patológicos que aparecem na via que prejudicam o seu efetivo desempenho.

As panelas, comumente chamadas de "buracos", foram um dos principais e mais prejudiciais danos patológicos encontrados na avenida, pois além de atrapalhar o fluxo do trânsito na via ainda são um risco à segurança dos usuários. Foram detectadas pequenas manifestações desse tipo patológico ao longo do trecho analisado (Figura 1), apesar da maioria possuir pequenas dimensões, elas ganharam destaque por aparecerem com outras patologias ao seu redor, além de ficarem próximas à pontos comerciais.

Figura 1. Panelas da Avenida Maria Merandoilina.

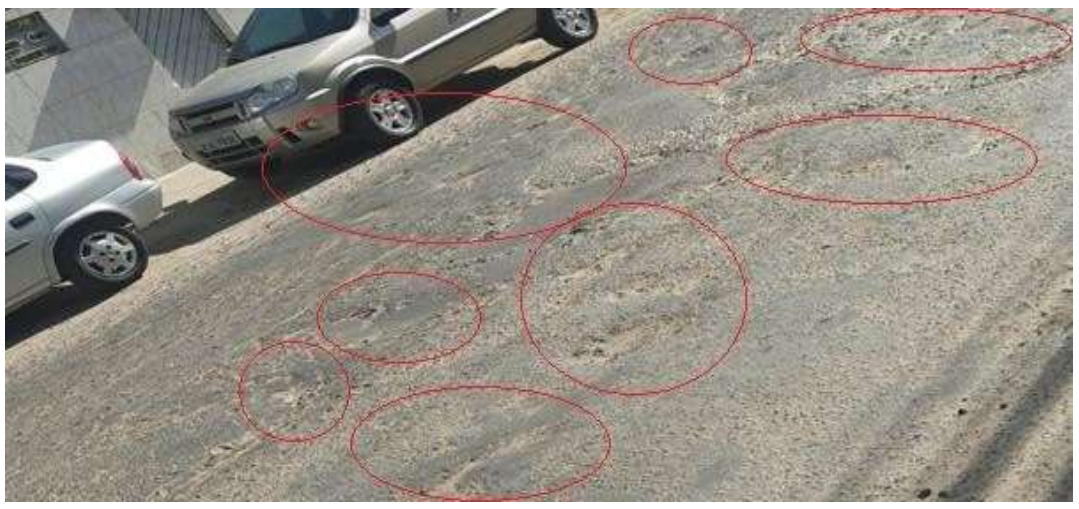

Fonte: Barbosa e Lima (2020). 
Na Figura 2, pode-se notar as trincas isoladas, geralmente vistas como patologias simplórias, entretanto, podem vir a se modificarem e evoluírem, ao se agruparem e se transformarem em trincas couro-de-jacaré, que se trata de um agrupamento de diversas trincas. Durante o levantamento, as trincas isoladas, aparecem em menor quantidade, apenas em 06 pontos ao longo da avenida.

Figura 2. Trincas isoladas da Avenida Maria Merandoilina.

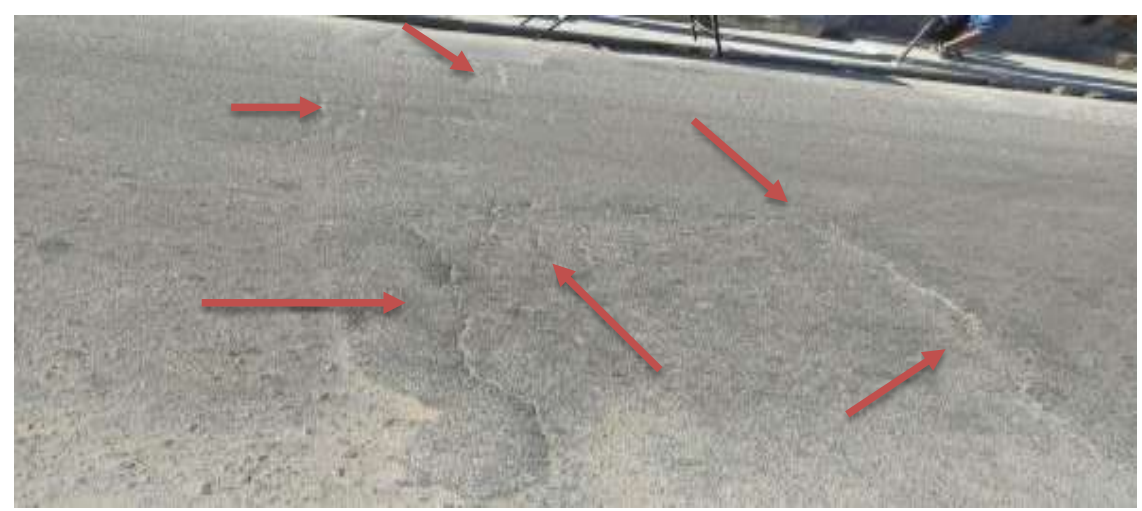

Fonte: Barbosa e Lima (2020).

Já as trincas couro-de-jacaré, conforme a Figura 3, foram observadas por toda a via e em longos trechos ininterruptos, apresentando trechos com longas anomalias e extremamente críticos.

Figura 3. Trincas couro de jacaré da Avenida Maria Merandoilina.

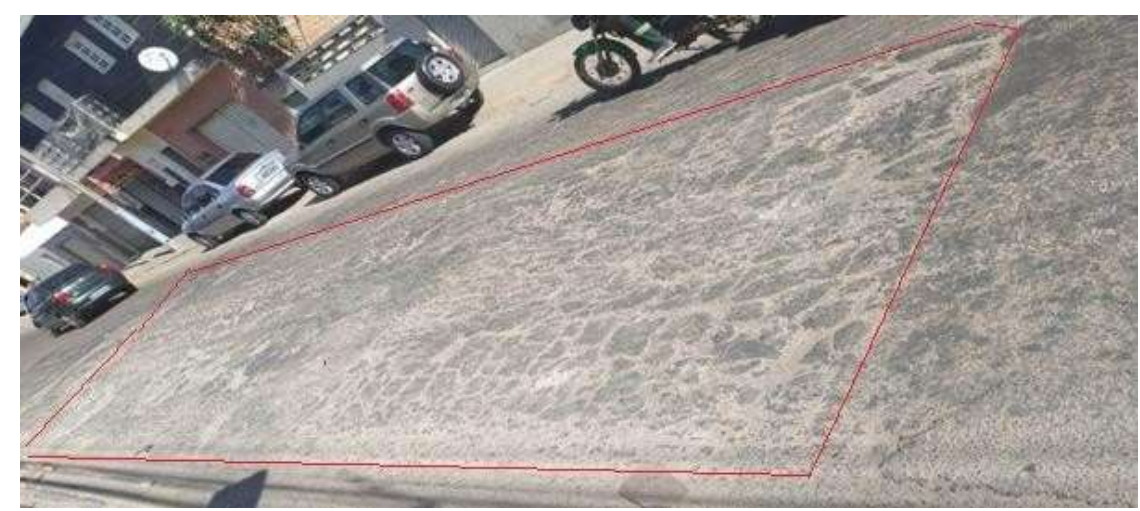

Fonte: Barbosa e Lima (2020).

Identificou-se os remendos, definidos por Adlinge e Gupta (2013) como uma parcela da pavimentação que precisou ser retirada e substituída afim de mitigar outras patologias bem como para cobrir alguma vala de serviço público, diversas vezes ao longo da via de estudo. Onde em alguns pontos utilizaram os remendos afim de reparar danos anteriores (Figura 4), evidenciando o elevado índice de desgastes e imperfeições presentes na avenida devido à sua quantidade de repetições no decorrer do trecho. 
Figura 4. Remendos da Avenida Maria Merandoilina

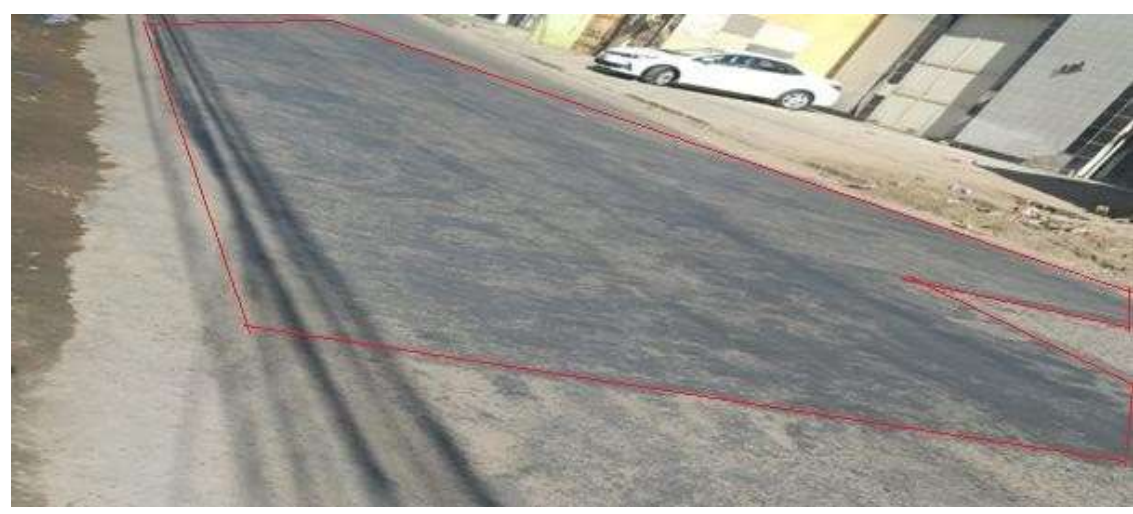

Fonte: Barbosa e Lima (2020).

Rebaixamentos na via, como ilustrado na Figura 5, onde é perceptível o desnivelamento da pista, apareceram com pouquíssima frequência, provavelmente pela ausência de adensamento das camadas inferiores bem como devido ao elevado índice de carregamento atuante ali, ocasionando assim um rebaixamento na avenida. Segundo Silva (2008), as principais causas dessa patologia são: o excesso de carga, o alto fluxo veicular e as altas temperaturas.

Figura 5. Afundamento da Avenida Maria Merandoilina.

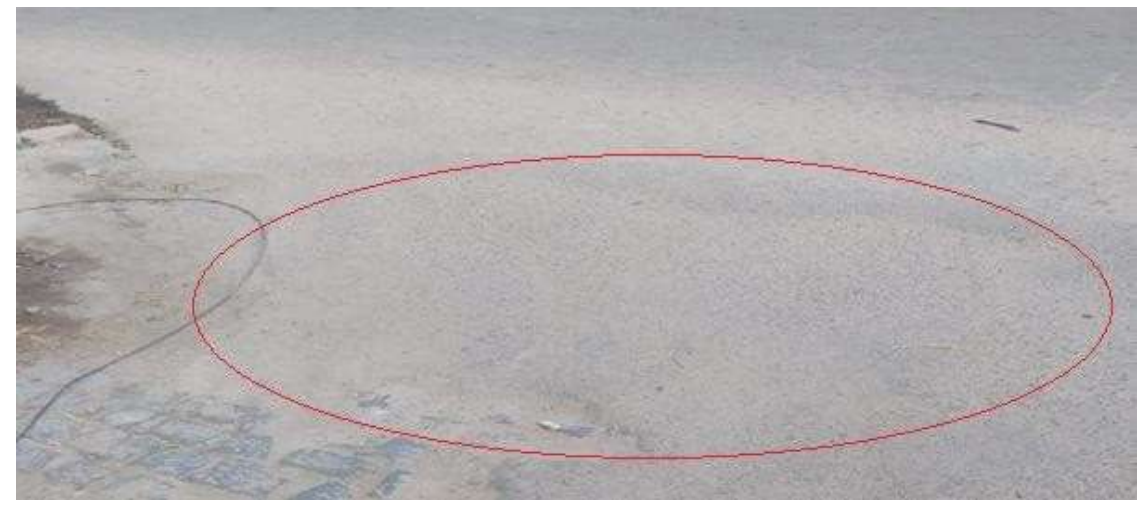

Fonte: Barbosa e Lima (2020).

Observou-se diversos pontos de ondulação ao longo do trecho em suas camadas superiores (Figura 6), que nada mais é o movimento plástico da camada de revestimento, ou seja, é uma deformidade na superficie da via com formato de "ondas" advindas do elevamento da malha asfáltica seja por: má excusão de projeto, concreto de baixa qualidade, problemas no solo ou até mesmo por frenagem constante de veículos pesados (Vila Betume, 2021). De acordo com Rocha (2009), necessita realizar a fresagem e o recapemanto para mitigar esse tipo de dano patológico. 
Figura 6. Ondulações da Avenida Maria Merandoilina.

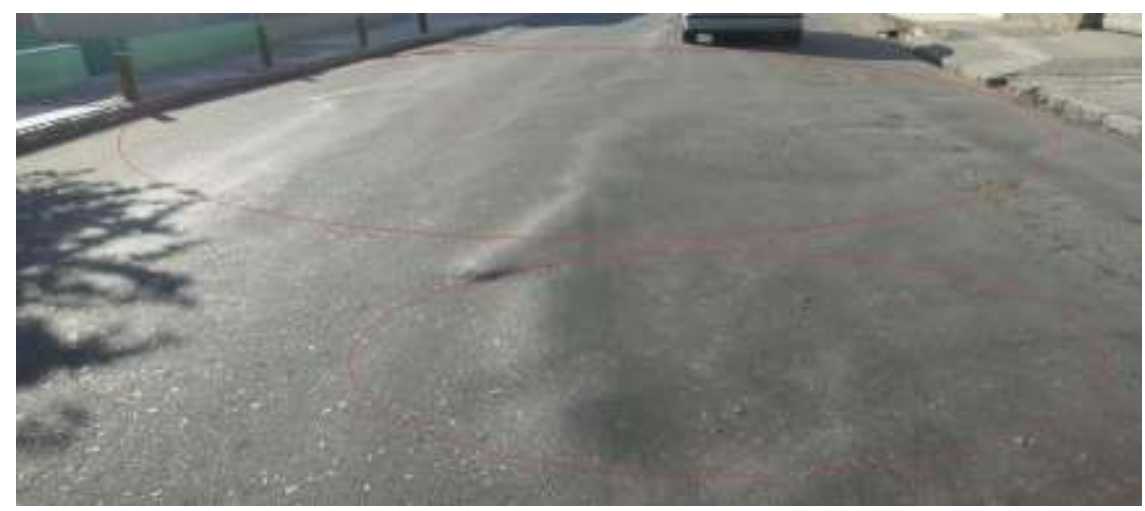

Fonte: Barbosa e Lima (2020).

A Figura 7 demonstra o desgaste superficial da avenida, que é um tipo patológico que é ponto de partida para outras patologias, visto que se trata do resultado do constante arrancamento do agregado do pavimento (CNT, 2018). Foi observado em abundância por todo o trecho de estudo, tendo sido visto em pequenas e grandes escalas, danificando a via e causando desconforto ao fluxo por todo o trecho. Causado principalmente pela redução da ligação e a baixa da adesividade entre o agregado e o ligante, bem como a existência de água na parte interna do revestimento e falhas na execução devido às más condições climáticas e até mesmo na manipulação do material asfáltico nos serviços por penetração (DNIT, 2005).

Figura 7. Desgaste do pavimento da Avenida Maria Merandoilina.

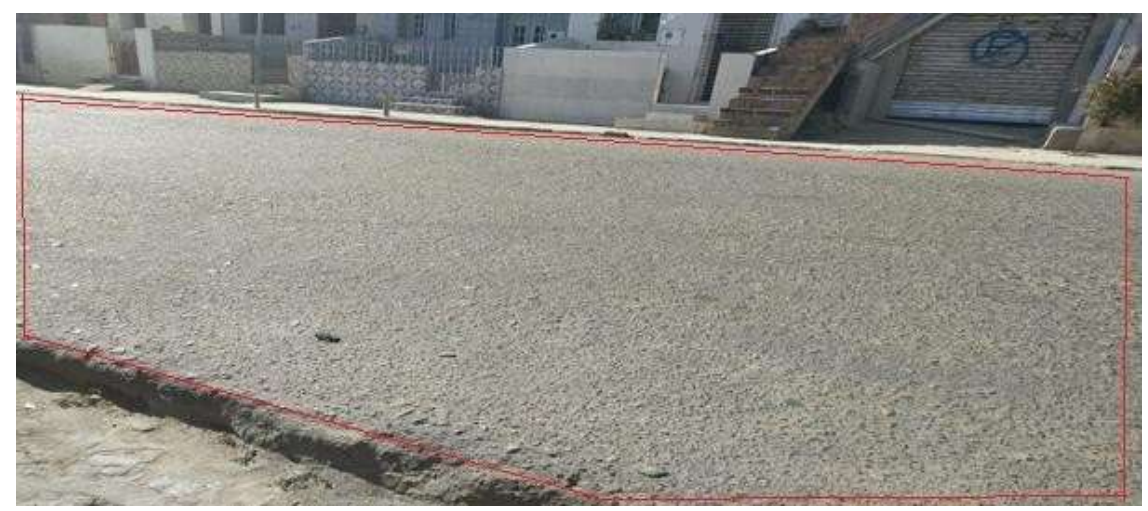

Fonte: Barbosa e Lima (2020).

No começo da via, apesar da pouca frequência, as exsudações (Figura 8) receberam destaque, pois apesar de serem visualizadas apenas em 4 casos, apareceram juntamente com ondulações ou escorregamentos próximos, advinda provavelmente, conforme cita Pinheiro (2019), pelo excesso de ligantes no asfalto e por meio de altas temperaturas que fazem com que esses ligantes, por não conseguirem ocupar espaços vazios ou apenas pelo seu excesso, migrem para a superfície da pista de rolamento provocando desconforto visual aos usuários. 
Figura 8. Exsudações da Avenida Maria Merandoilina.

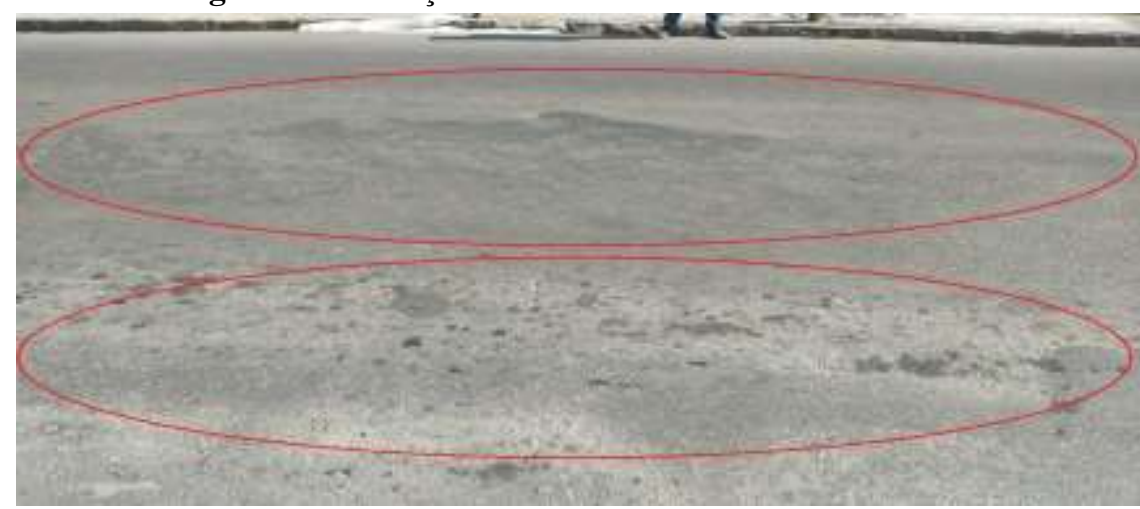

Fonte: Barbosa e Lima (2020).

Assim como as exsudações, os escorregamentos (Figura 9), tipo de patologia que provoca um desnivelamento nas laterais da pavimentação, provocados provavelmente pela ausência de aderência entre as camadas de revestimento e a subjacente ou até mesmo devido à baixa resistência do material asfáltico utilizado. (Ramos, 2017) Essas falhas costumam aparecer geralmente em locais de frenagem e de intersecções, ainda de acordo com Ramos (2017), pois a movimentação de veículos tende a causar o deslizamento ou a deformação da massa asfáltica, devido sua baixa aderência ou resistência. Os escorregamentos apareceram em maior frequência no início da via, nas proximidades da ponte, tornando bastante visível essa falha na estética da avenida, causando desconforto visual aos seus usuários.

Figura 9. Escorregamentos da Avenida Maria Merandoilina.

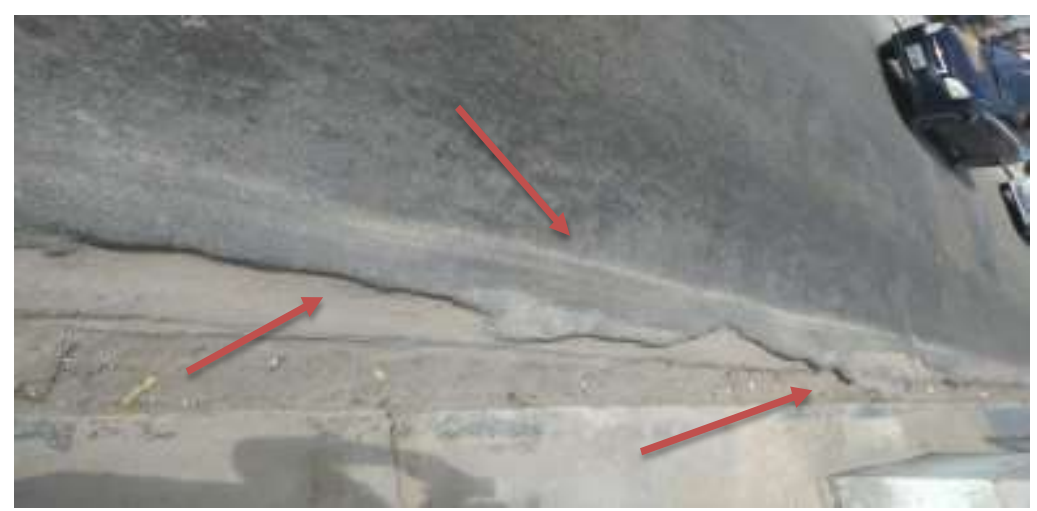

Fonte: Barbosa e Lima (2020).

A Tabela 4, refere-se ao levantamento patológico feito na Avenida Maria Merandoilina, relatando todas as patologias encontradas ao longo do trecho de estudo. Nota-se o nível de deterioração da pista de rolamento através da quantidade elevada de remendos que foram notificados na via, sendo estes, reparos contínuos de patologias antigas, o que evidencia a frequência do surgimento de patologias na avenida devido a intemperismos e/ou danos sofridos. 
Tabela 4. Levantamento das patologias na Avenida Maria Merandoilina.

\begin{tabular}{|c|c|c|}
\hline CODIFICAÇÃO & TIPO & QUANTITATIVO \\
\hline$P$ & Panela & 9 \\
\hline TR & Trinca Isolada & 6 \\
\hline $\mathrm{TJ}$ & Trinca Couro de Jacaré & 24 \\
\hline $\mathrm{R}$ & Remendo & 30 \\
\hline $\mathrm{AF}$ & Afundamento & 1 \\
\hline $\mathrm{O}$ & Ondulação & 7 \\
\hline $\mathrm{D}$ & Desgaste do pavimento & 34 \\
\hline EX & Exsudação & 4 \\
\hline $\mathrm{E}$ & Escorregamento & 3 \\
\hline
\end{tabular}

Fonte: Barbosa e Lima (2020).

\subsection{Método de classificação visual aplicado na avenida}

O levantamento visual contínuo, seguiu sua elaboração de acordo com a normatização do DNIT (2003), onde foi realizado o preenchimento do formulário disponibilizado pelo próprio DNIT (Anexo B), constando todas as patologias identificadas ao longo do trecho da via em estudo, assinalando-as conforme sua tipologia e utilizando as instruções dos itens a seguir.

Utilizando os dados do levantamento patológico (Tabela 4), que possui a quantidade geral das patologias presentes na via, coletou-se o quantitativo de remendos e panelas, que em conjunto possuem um total de 39 repetições patológicas ao longo do trecho analisado; utilizando a Tabela 2 para coleta do código e da frequência que formam o valor do ICPF, sendo classificada a frequência como alta, por possuir uma quantidade/quilômetro superior a 5, e nível 3 de gravidade.

As demais falhas presentes na Avenida Maria Merandoilina, trincas isoladas e de couro-de-jacaré, afundamentos, ondulações, desgastes do asfalto, exsudações e escorregamentos, totalizaram 79 pontos, fazendo com que também seja classificada como alta e de nível de gravidade 3, pois apresenta porcentagem por $\mathrm{Km}$ superior a 50\%, totalizando $77 \%$ que se diz respeito aos 79 pontos patológico do total de 118 apresentados na via.

Por meio da classificação do índice de gravidade que é alta, conforme Tabela 2, consegue-se determinar os valores de "Pt", "Poap" e "Ppr" sendo estes iguais à 0,65, 1 e 1, respectivamente, como consta na Tabela 3. Utiliza-se esses dados para obter as frequências através do cálculo de "Ft" utilizando a porcentagem proporcional dos demais defeitos presentes na Tabela 2, ou seja, 0,77 (77\%) conforme comentado anteriormente, onde utiliza-se também 0,77 para o "Foap" e 39 para o "Fpr", que corresponde ao quantitativo de remendos e panelas presentes na via.

Portanto, ao seguir os passos citados à cima, chegou-se ao cálculo do IGGE, através da expressão seguinte:

$$
\begin{aligned}
& \text { IGGE }=(\text { Pt x Ft })+(\text { Poap x Foap })+(\text { Ppr }+ \text { Fpr }) \\
& \text { IGGE }=(0,65 \times 0,77)+(1 \times 0,77)+(39+1) \\
& \text { IGGE }=40,3
\end{aligned}
$$

Para a caracterização e classificação dos reparos necessários para a via, utiliza-se a condição do ICPF de conceito ruim, cujo se faz necessário o uso de recapeamento com correções prévias, que são correções antecipadas de falhas generalizadas em pontos específicos, sendo remendos superficiais ou profundos, utilizando ICPF com valor de 1,5 conforme a Tabela 5 . 
Tabela 5. Preenchimento da frequência de defeitos.

\begin{tabular}{|c|c|c|c|c|c|c|c|c|c|c|}
\hline \multicolumn{10}{|c|}{ FREQUÊNCIA DE DEFEITOS (A, M, B OU S) } & \multirow{3}{*}{ ICPF } \\
\hline \multirow[t]{2}{*}{$\mathrm{P}$} & \multicolumn{3}{|c|}{ TRINCAS } & \multirow[t]{2}{*}{$\mathrm{R}$} & \multicolumn{2}{|c|}{ DEFORMAÇÕES } & \multicolumn{3}{|c|}{ OUTROS DEFEITOS } & \\
\hline & TR & $\mathrm{TJ}$ & TB & & $\mathrm{AF}$ & $\mathrm{O}$ & $\mathrm{D}$ & EX & $\mathrm{E}$ & \\
\hline A & B & $\mathrm{M}$ & $\mathrm{S}$ & A & B & $\mathrm{B}$ & $\mathrm{A}$ & B & $\mathrm{B}$ & 1,5 \\
\hline
\end{tabular}

Fonte: Barbosa e Lima (2020).

Utilizou-se as informações obtidas no IGGE e ICPF, através da relação comparativa desses dados, presentes na Tabela 3, para encontrar o valor do IES. A avenida possui um IGGE de 40,3, ficando entre a classificação de 40 e 60 , e com um ICPF de 1,5 que é menor que os 2,5 presentes no comparativo da Tabela 4, são esses os valores decisivos para a determinação do IES que corresponde a 5, cujo valor encontrado por meio da metodologia LVC, dos dados coletados e dos cálculos executados, classifica a via de estudo como ruim e de código D.

\section{Conclusão}

As patologias em vias asfálticas tendem a atrapalhar significativamente o fluxo e a qualidade da camada de rolamento, visto a quantidade crescente de veículos que transitam por elas, e de acordo com a intensidade e nível patológico existente na via, consegue-se classificá-la como ótima, boa, regular, ruim ou péssima.

O trabalho abordou e investigou as falhas oriundas das camadas da pavimentação flexível, onde retratou-se as classificações de cada tipo patológico identificado, considerando até mesmo o método LVC, que consiste na classificação da vida útil de uma avenida, bem como seu estado geral, devido a gravidade patológica, visando os reparos necessários conforme a tipologia dos danos, além de criar com auxílio das normas nacionais um parecer técnico.

Neste método conseguiu-se avaliar que a Avenida Maria Merandoilina, que pela sua alta frequência de defeitos obteve conceito ruim, necessitando de recapeamento com correções prévias em áreas localizadas, remendos superficiais ou profundos. As principais patologias que foram vistas na avenida e que mais influenciaram para classificação negativa da via, foram as trincas couro de jacaré, remendos e desgastes, devido a sua alta repetição.

Com isso evidencia-se o diagnóstico tanto individual de cada patologia do trecho, assim como, de maneira geral as condições reais que a via se encontra, a qual houve uma discussão quanto ao impacto de cada manifestação em seu revestimento asfáltico através dos índices IGGE, ICPF e IES, onde conseguiu-se gerar uma classificação indicativa, além de ressaltar os pontos que estão defeituosos e um parecer que possa indicar os danos e defeitos, para posteriormente serem sanados e melhorar as condições de segurança, mobilidade e conforto de todos os habitantes e condutores circunvizinhos.

Diante de todo o exposto, espera-se que o presente trabalho sirva de embasamento para futuras pesquisas, tanto com o teor investigativo em outras áreas, que possuem similaridades, como também na continuidade de pesquisas acerca das patologias identificadas na via em questão, e das possíveis formas de prevenção, manutenção e correção. Sugere-se, para pesquisas futuras, a realização desta classificação e diagnóstico em regiões próximas à área de estudo, fazendo-se um comparativo do estado de conservação das regiões levantadas, como também a criação de um mapa de dano da via, identificando e diferenciando os tipos de patologias encontradas e o grau de risco que estas podem causar aos que nela trafegam. 
Research, Society and Development, v. 10, n. 17, e212101724257, 2021

(CC BY 4.0) | ISSN 2525-3409 | DOI: http://dx.doi.org/10.33448/rsd-v10i17.24257

\section{Referências}

Adlinge, S. S. \& Gupta, A. K. (2013). Pavement Deterioration and its Causes. Journal of Mechanical \& Civil Engineering,

Barbosa, C. E. B. \& Lima, J. J. (2020). Avaliação das Manifestações Patológicas em Revestimentos Asfálticos da Avenida Maria Merandoilina na Cidade de Caruaru-pe. Trabalho de Conclusão de Curso em Engenharia Civil , UNINASSAU CARUARU.

Bernucci, L. et al. (2006). Pavimentação Asfáltica: formação básica para engenheiros. Petrobrás e ABEDA., 504 p.

CNT (Org). (2018). Conheça os 13 principais defeitos do pavimento das rodovias. https://www.cnt.org.br/agencia-cnt/conheca-principais-defeitos-pavimento.

CNT (Org.). (2016). Pesquisa CNT de rodovias 2016: Pesquisa CNT aponta 58,2\% das rodovias com problemas. https://www.cnt.org.br/agencia$\mathrm{cnt} /$ pesquisa-cnt-aponta-58-das-rodovias-com-problemas

CNT (Org). (2017). Transporte rodoviário: por que os pavimentos das rodovias do Brasil não duram? https://cnt.org.br/agencia-cnt/cnt-divulga-estudo-porque-pavimento-rodovias-brasil-nao-duram-resultados

DNIT - Departamento Nacional de Infraestrutura de Transportes. (2003). Levantamento visual contínuo para avaliação da superfície de pavimentos flexíveis e semi-rígidos Procedimento. Ministério dos Transportes. Diretoria de Planejamento e Pesquisa. Coordenação Geral de Estudos e Pesquisa. Instituto de Pesquisas Rodoviárias. Brasil, 11 p.

DNIT - Departamento Nacional de Infraestrutura de Transportes. (2005). Manual de conservação rodoviária. Diretoria de Planejamento e Pesquisa. Coordenação Geral de Estudos e Pesquisa. Instituto de Pesquisas Rodoviárias. 564 p.

DNIT - Departamento Nacional de Infraestrutura de Transportes. (2006). Manual de pavimentação. Diretoria de Planejamento e Pesquisa. Coordenação Geral de Estudos e Pesquisa. Instituto de Pesquisas Rodoviárias. 274 p.

Pereira, H. (2018). Patologias em pavimentos asfálticos e determinação do grau de deterioração asfáltica em trechos de tráfego de veículos pesados. Trabalho de Conclusão de Curso em Engenharia Civil, Centro Universitário de Maringá/UNICESUMAR.

Pinheiro, I. (2019). As patologias mais comuns nas estradas. https://www.inovacivil.com.br/as-patologias-mais-comuns-nas-estradas/

Ramos, D. M. (2017). Determinação de patologias em pavimentação asfáltica nas avenidas: av. Sergipe, av. Joaquim aires, av. Das nações unidas em porto nacional-TO. Trabalho de Conclusão de Curso em Engenharia Civil, Centro Universitário Luterano de Palmas.

Ribas, L. C. (2017). Custo-benefício na execução de pavimentos rígidos. Trabalho de Conclusão de Curso em Engenharia Civil, Universidade Tuiuti do Paraná/UTP.

Rocha, J. P., Ferreira, L. G. C. M. \& Borba, F. V. (2019). Diagnóstico de patologias encontradas em pavimentos rodoviários flexíveis e semirígidos. Enciclopédia Biosfera, Centro Científico Conhecer - Goiânia, 16 (30), 199-200.

Rocha, R. S. (2009). Patologias de pavimentos asfálticos e suas recuperações - estudo de caso da avenida pinto de aguiar. Trabalho de Conclusão de Curso em Engenharia Civil, Universidade Católica de Salvador.

Silva, P. F. A. (2008). Manual de patologia e manutenção de pavimentos. (2a ed.), PINI, 28p.

Silva, J. C. L. (2020). A estratégia brasileira de privilegiar as rodovias em detrimentodas ferrovias. https://brasilescola.uol.com.br/geografia/por-que-brasiladotou-utilizacao-das-rodovias-ao-inves-.htm

Vila Betume. (2021). Ondulações no asfalto / Entenda as principais causas. https://vilabetume.com.br/ondulacoes-no-asfalto-entenda-as-principais-causas/

Votorantim. (2016). Conheça os diferentes tipos de pavimentos para vias públicas. https://www.mapadaobra.com.br/capacitacao/conheca-os-diferentes-tiposde-pavimentos-para-vias-publicas/?doing_wp_cron=1602021408.1929121017456054687500 